\title{
MBAs: cinco discursos em busca de uma nova narrativa
}

\author{
MBAs: Five discourses in search of a new narrative
}

Thomaz Wood Jr. ${ }^{1}$

Julia Fernandes Personini Cruz ${ }^{2}$

\begin{abstract}
Resumo
A indústria do management evoluiu significativamente no Brasil, desde os anos 1990, disseminando ideias e modelos de gestão. O fenômeno despertou o interesse de pesquisadores, que desenvolveram estudos sobre seus "pilares": as empresas de consultoria, a mídia de negócios, os gurus de gestão e as escolas de negócios - este último, objeto de estudo neste trabalho. Nas últimas décadas, multiplicaram-se no Brasil os programas de pós-graduação em formação gerencial: os chamados MBAs. Nos Estados Unidos e na Europa, tais programas têm sido alvo de escrutínio e de estudos científicos de natureza reflexiva e crítica. No Brasil, entretanto, poucos estudos foram realizados a respeito. Este artigo almeja preencher essa lacuna. Para isso, identificamos e apresentamos os discursos mais salientes produzidos sobre tais cursos: o discurso da crítica instrumental, o discurso da defesa instrumental, o discurso crítico de emancipação e o discurso da redenção da mídia de negócios. Além disso, também apresentamos o discurso dos alunos. Para isso, realizamos uma pesquisa com alunos de três programas brasileiros e captamos suas percepções. Concluímos que MBA pode ser visto como um campo institucional aberto, no qual diferentes agentes empregam distintas estratégias discursivas, de acordo com suas perspectivas ontológicas e seus interesses. Observamos que há pouca interação ou disputa direta entre os discursos. Entretanto, podemos identificar elementos para uma renovação da "narrativa do MBA". A nova narrativa tem como personagem um indivíduo socialmente consciente e responsável, dotado de uma ambição de mudança pessoal e profissional e que aspira a uma posição sênior de liderança ou, alternativamente, o empreendedorismo. Esse indivíduo passa por experiências que unem teoria e prática, que compreendem contextos culturais diversos e o desenvolvimento de uma visão crítica sobre as organizações e a atividade gerencial.
\end{abstract}

Palavras-chave: MBA. Análise do discurso. Narrativas. Indústria do management. Institucionalização.

Artigo submetido em 18 de junho de 2013 e aceito para publicação em 20 de dezembro de 2013.

O título deste artigo inspira-se na obra do dramaturgo e romancista italiano Luigi Pirandello: Seis personagens à procura de um autor. Escrita em 1921, a peça narra um ensaio de teatro que é invadido por seis personagens à procura do diretor para convencê-lo a encenar suas vidas. Neste artigo, os "personagens" são cinco vozes caracterizadas por discursos que identificamos na literatura científica, na mídia de negócios e entre alunos de programas de MBA. Estes "personagens" buscam influenciar a realidade, construindo ou reconstruindo uma narrativa consistente e atraente. Tal busca, acreditamos, constitui um caminho em curso e uma tarefa marcada pela multiplicidade de alternativas.

1 Doutor em administração pela Fundação Getulio Vargas/EAESP; Professor titular da Fundação Getulio Vargas/EAESP. Endereço: FGV/EAESP - Escola de Administração de Empresas de São Paulo, Avenida Nove de Julho, 2029, Bela Vista, CEP 01313-902, São Paulo - SP, Brasil. E-mail: thomaz.wood@fgv.br

${ }^{2}$ Mestre em administração pela Fundação Getulio Vargas/EAESP. Endereço: FGV/EAESP - Escola de Administração de Empresas de São Paulo, Avenida Nove de Julho, 2029, Bela Vista, CEP 01313-902, São Paulo - SP, Brasil. E-mail: julia personini@yahoo.com.br 


\begin{abstract}
The management industry has significantly evolved in Brazil, since the 1990s, spreading ideas and management models. The phenomenon has sparked the interest of researchers, who carried out studies on its "pillars": consulting firms, business media, management gurus, and business schools - the latter constitutes the study object in this paper. In the last decades, the number of graduate programs in management education has been multiplied in Brazil: the so-called MBAs. In the United States and Europe, such programs have been subject to scrutiny and scientific studies having a reflective and critical nature. In Brazil, however, few studies have been conducted about them. This article aims to fill this gap. For this, we identify and present the most pronounced discourses produced about such courses: the discourse of instrumental criticism, the discourse of instrumental defense, the critical discourse of emancipation, and the discourse of redemption of the business media. Besides, we also present the discourse of students. For this, we conducted a survey with students from three Brazilian programs and collected their perceptions. We conclude that a MBA may be seen as an open institutional field, where various agents employ different discursive strategies, according to their ontological perspectives and interests. We observe that there is little direct interaction or argument between the discourses. However, we may identify elements for a renewalof the "narrative of MBA". The new narrative has as its character a socially conscious and responsible individual, who has an ambition for personal and professional change and pursuesa senior leadership position or, alternatively, entrepreneurship. This individual goes through experiences that combine theory and practice, which comprise various cultural contexts and the development of a critical view on organizations and the managerial activity.
\end{abstract}

Keywords: MBA. Discourse analysis. Narratives. Management industry. Institutionalization.

\title{
Introdução
}

Nas últimas décadas, ocorreu considerável desenvolvimento da indústria do management, um campo institucional em transformação (GREENWOOD, SUDDABY e HININGS, 2002), composto por quatro pilares que se relacionam e se reforçam mutuamente: as empresas de consultoria, a mídia de negócios, os gurus de gestão e as escolas de negócios (MICKLETHWAIT e WOOLDRIDGE, 1998). Tal desenvolvimento foi permeado, e ao mesmo tempo ajudou a consolidar, a cultura do management, que pode ser definida como um conjunto de pressupostos partilhados pelas empresas e pela sociedade, e inclui: primeiro, uma crença na liberdade de mercado; segundo, uma visão dos indivíduos como empreendedores; terceiro, a busca pela excelência como meio para a melhoria individual e coletiva; quarto, o uso maciço de símbolos e palavras de ordem para promover ideais de comportamento; e quinto, a visão segundo a qual o conhecimento sobre gestão é capaz de racionalizar e aperfeiçoar todas as atividades organizadas (PAES DE PAULA e WOOD JR., 2002).

O tema do desenvolvimento da indústria do management despertou o interesse de pesquisadores brasileiros, que investigaram os pilares citados acima: as escolas de negócios e os programas de formação gerencial (RUAS e COMINI, 2007; WOOD JR. e PAES DE PAULA, 2004), as empresas de consultoria (DONADONE, 2010; WOOD JR. e CALDAS, 2005), a mídia de negócios (COSTA, BARROS e MARTINS, 2012; FONTENELLE, 2012; WOOD JR. e PAES DE PAULA, 2008) e os gurus de gestão empresarial (COOKE, WOOD JR. e MACAU, 2013; DONADONE, 2000). Neste trabalho focalizamos o pilar das escolas de negócios, ainda relativamente pouco explorado em trabalhos científicos no Brasil.

As escolas de negócios surgiram nos Estados Unidos há mais de um século, chegaram ao Brasil na década de 1950 e tiveram enorme desenvolvimento no país a partir dos anos 1990. No processo de expansão, que aconteceu em muitos países, os MBAs se consolidaram como produto de grande sucesso para as instituições de ensino, como cursos supostamente capazes de alavancar as carreiras dos estudantes, e como alternativa educacional para formar líderes para as empresas. Os MBAs tornaram-se, ainda, para a mídia de negócios, objeto constante de matérias e fonte de receita publicitária. 
A Association of MBAs (AMBA), entidade certificadora de programas, define MBA como um programa de pós-graduação generalista, com nível de mestrado, duração mínima de um ano (cursos em tempo integral) ou dois anos (cursos em tempo parcial) e carga horária superior a 1.800 horas, incluindo e estudo extraclasse. $\mathrm{O}$ currículo de um MBA deve ter, como foco, liderança, por meio da gestão estratégica e do desenvolvimento da carreira profissional, e apresentar orientação prática (ASSOCIATION OF MBAS, 2012). Há, atualmente, grande variedade de programas sob a nomenclatura MBA: cursos generalistas, cursos especializados, e cursos generalistas com opções de especialização (veja HUNT e SPECK, 1986).

Observa-se notável influência norte-americana no desenvolvimento do ensino em Administração e, especificamente, na criação dos MBAs no Brasil (OLIVEIRA, 2008). Entretanto, as versões brasileiras apresentam particularidades relevantes, tais como a prevalência de programas de tempo parcial e a existência de duas categorias: os cursos de extensão lato sensu, que compõem a maioria das ofertas, e os programas stricto sensu, que incluem os mestrados profissionais: os MPAs. Além disso, entre nós a sigla passou a ser adotada com grande liberdade, nem sempre se referindo a programas com a definição proposta pela AMBA.

No exterior, em especial nos Estados Unidos, desenvolveu-se vasta literatura reflexiva e crítica em relação aos MBAs. Diversos pesquisadores questionam a relevância dos MBAs para a carreira dos alunos e para a prática da gestão (PFEFFER e FONG, 2002). Critica-se, também, a ênfase excessiva dada à teoria e ao rigor científico, em vez de à prática (BENNIS e O'TOOLE, 2005), e a importância exagerada às disciplinas técnicas (hard skills) em relação às comportamentais (soft skills) (GOSLING e MINTZBERG, 2006). Adicionalmente, é apontado o risco de jovens sem experiência se considerarem aptos a gerir negócios e pessoas (MINTZBERG, 2004). Finalmente, desenvolveu-se uma corrente crítica de base ideológica, que condena a disseminação de crenças e valores relacionados à cultura do management (WOOD JR. e PAES DE PAULA, 2008).

Em resposta à parte dessas críticas, surgiram pesquisas com o objetivo de avaliar o impacto dos MBAs no desempenho profissional e na carreira dos alunos. Foram realizados estudos focados em comparar o desempenho de executivos que realizaram MBA com o de executivos que não o fizeram (SLATER e DIXON-FOWLER, 2010), avaliar o peso dado às competências gerenciais mais importantes nas grades curriculares dos cursos (RUBIN e DIERDORFF, 2009), e entender a base do conhecimento aplicado em gestão (BALDWIN, PIERCE, JOINES et al., 2011). Surgiram, também, propostas para adicionar uma perspectiva crítica e humanista ao ensino de negócios (FOX, 1994; GREY e MITEV, 1995; WILLMOTT, 1994).

Neste artigo, procuramos sintetizar e apresentar os discursos produzidos sobre os MBAs: o discurso da crítica instrumental, o discurso da defesa instrumental, o discurso crítico de emancipação e o discurso da mídia de negócio. Além disso, apresentamos também o discurso dos alunos. Para isso, realizamos uma pesquisa com alunos de três programas brasileiros, e captamos suas percepções sobre os programas.

Organizamos o texto em cinco seções, incluindo esta introdução. Na segunda seção apresentamos os quatro primeiros discursos mencionados. Na terceira, os métodos e os resultados da pesquisa sobre o discurso dos alunos. Na quinta seção, discutimos os cinco discursos e a possibilidade de renovação da "narrativa do MBA". Na sexta seção apresentamos uma síntese do artigo, explicitamos suas contribuições, registramos suas limitações e indicamos caminhos para futuros estudos.

\section{Quatro Discursos Estabelecidos}

A identificação e análise dos quatro discursos apresentados a seguir fundamentaram-se no crescente corpo de literatura sobre discurso e narrativa (ALVESSON e KÄRREMAN, 2000; HARDY e PHILLIPS, 1999; MAGUIRE e HARDY, 2006; PHILLIPS e HARDY, 2002). Baseamo-nos em trabalhos anteriores sobre MBAs (PERSONINI CRUZ, 2013; WOOD JR. e PAES DE PAULA, 2004), atualizando e ampliando os 
levantamentos realizados. Inicialmente, com base em um exame geral dos textos sobre MBAs publicados em revistas científicas (especialmente nos periódicos Management Learning e Academy of Management Learning \& Education, a partir da década de 1990) e na mídia de negócios (especialmente nas revistas Exame e Você S.A., também a partir da década de 1990), procuramos definir os diferentes discursos, identificando o foco central de cada um deles. Em seguida, aprofundamos a análise de cada discurso, revendo seus respectivos textos, e identificando e sistematizando seus temas preferenciais.

\section{O discurso da crítica instrumental}

A história dos MBAs foi marcada por críticas. O questionamento sobre o impacto destes cursos na carreira e no desempenho dos profissionais surgiu no início do século XX. Naquele momento inicial, a crítica relacionava-se ao fato de o corpo docente ser formado por acadêmicos, especialmente economistas, psicólogos, sociólogos e cientistas políticos, os quais nem sempre tinham experiência prática. Para aproximar a teoria da prática, passou-se a utilizar exemplos, o que, na década de 1920, evoluiu para o método de estudo de caso, técnica que se popularizou nas décadas seguintes (MINTZBERG, 2004).

No final da década de 1940, as fundações Ford e Carnegie divulgaram relatórios, denunciando a irrelevância e a inconsistência científica das pesquisas e teorias geradas pelas escolas de negócios (BENNIS e O'TOOLE, 2005). Os relatórios recomendavam ações para que as escolas recuperassem a sua relevância e o seu prestígio acadêmico. Entre as mudanças indicadas, defendiam-se o uso de ferramentas analíticas e de pesquisa nas disciplinas fundamentais, a formação em ciências sociais, matemática e estatística, e a necessidade de incentivar os alunos a aplicar essas ferramentas em problemas reais de negócios. A partir daí, as escolas de negócios investiram na produção acadêmica e ganharam prestígio.

Entretanto, ao corrigir os problemas apontados, novos problemas surgiram. Na década de 1980, Porter e McKibbin (1988) questionaram a grade curricular por ser muito focada em desenvolver a capacidade analítica e dar pouca ênfase à solução de problemas. Uma década mais tarde, as críticas concentraram-se na incapacidade dos programas de MBA de desenvolver soft skills, como liderança e relacionamento interpessoal, e no excessivo foco dado aos hard skills (GOSLING e MINTZBERG, 2006).

Nos anos 2000, as críticas intensificaram-se, especialmente nos Estados Unidos. No início daquela década, Pfeffer e Fong (2002) publicaram o polêmico artigo The Endof Business Schools? Less Success Than Meets the Eye, no qual questionavam a relevância dos MBAs na carreira dos alunos. Os autores sugeriam que a posse de um certificado de MBA não resultava em um avanço maior ou mais rápido na carreira e não garantia um melhor desempenho profissional.

Bennis e O'Toole (2005), por sua vez, criticaram o rigor científico das escolas de negócios e sua distância das necessidades práticas das empresas. Eles defenderam uma mudança nos MBAs focando a demanda dos alunos: aprender a interpretar fatos e tomar decisões na ausência de informações claras. De forma similar, Rubin e Dierdorff (2009) identificaram as seis competências mais demandadas pelas empresas e classificaram as disciplinas dos MBAs de 373 escolas segundo essas competências. Os autores concluíram que os programas não priorizavam, em suas grades curriculares, as competências gerenciais mais demandadas.

Complementarmente, Baldwin, Pierce, Joines et al. (2011) realizaram uma pesquisa com mais de 23 mil gestores e estudantes (aspirantes a gestores), constatando que a relação entre a experiência profissional e o conhecimento aplicado é modesta. A conclusão incorporou-se ao debate sobre a validade da gestão como profissão e a dificuldade de se desenvolverem gestores em sala de aula.

Para Mintzberg (2004), que se notabilizou por críticas contundentes contra os MBAs, as habilidades de gestão são desenvolvidas com a experiência, não sendo possível criar um gestor em uma sala de aula. $\mathrm{O}$ autor critica o fato de o corpo discente dos MBAs ser composto por estudantes muito jovens e pouco 
experientes. Mintzberg critica, também, a estrutura e os métodos dos programas. Segundo ele, o uso de estudos de caso restringe a Administração à análise de dados convenientemente estruturados e as organizações a um agrupamento de áreas funcionais operando sob uma estratégia simples.

\section{O discurso de defesa instrumental}

Em contraposição a algumas dessas críticas, foram realizadas diversas pesquisas e verificações de rankings que confirmaram o potencial dos MBAs em impactar o desempenho profissional e a carreira dos alunos. No que se refere ao impacto dos cursos na carreira dos alunos, os rankings das revistas de negócios divulgam periodicamente informações e estatísticas (BUSINESSWEEK, 2011; FINANCIAL TIMES, 2011). O ranking publicado pelo jornal britânico Financial Times apresenta o impacto dos programas na remuneração dos alunos, avaliando o incremento percentual de salário após a conclusão do curso em relação ao salário anterior ao ingresso. No ranking global dos cem melhores MBAs de 2013, por exemplo, em termos de aumento salarial, observa-se um incremento mínimo de $61 \%$ - entre alunos da University of Bath School of Management - e um incremento máximo de $163 \%$ - entre ex-alunos da Peking University Guanghua (FINANCIAL TIMES, 2011).

A AMBA, por sua vez, promove periodicamente uma pesquisa para avaliar o impacto de MBAs na carreira dos alunos. A entidade avalia duas categorias de impacto - salários e carreira - e considera diferentes momentos - antes da realização do curso, imediatamente após a conclusão, de três a cinco anos, e de seis a dez anos após a realização do curso. Entre as variáveis pesquisadas estão o salário médio, o crescimento salarial e as mudanças de carreira. Na pesquisa de 2010, com mais de dois mil ex-alunos de diversos países, inclusive brasileiros, observou-se que: primeiro, o crescimento salarial médio foi de $33 \%$, imediatamente após o MBA, de 92\%, de três a cinco anos após, e de 151\%, de seis a dez anos após o curso; segundo, há evidências de que houve progresso na carreira, com muitos ex-alunos assumindo posições seniores; terceiro, $42 \%$ dos respondentes informaram ter mudado de emprego imediatamente após completar o MBA; e quarto, $26 \%$ dos respondentes abriram negócio próprio (ASSOCIATION OF MBAS, 2010).

Pesquisa desenvolvida pelo Graduate Management Admission Council (GMAC) corroborou tais resultados. Em um levantamento realizado com 1.096 recrutadores de mais de 800 empresas em 40 países, o estudo destacou o crescimento do percentual de empresas em busca de alunos de MBAs (79\% dos recrutadores em 2012, em comparação a 72\% no ano anterior) e o fato de o salário anual de profissionais com MBA ter um prêmio médio de US\$ 50 mil em comparação ao salário de profissionais sem o título (GRADUATE MANAGEMENT ADMISSION COUNCIL, 2012).

Entre trabalhos acadêmicos, o estudo provavelmente mais amplo sobre o tema resultou no artigo de Zhao, Truell, Alexander et al. (2006), escrito em resposta ao artigo de Pfeffer e Fong (2002). Zhao, Truell, Alexander et al.(2006) realizaram uma pesquisa com mais de 300 ex-alunos de MBAs de escolas credenciadas pela The Association to Advance Collegiate Schools of Business (AACSB) - uma entidade certificadora - e formados entre 1996 e 2002. Os autores verificaram um impacto positivo na empregabilidade, na remuneração anual e em promoções de cargo. Além disso, observaram que ex-alunos percebem que seu desempenho é superior ao de seus pares que não cursaram MBAs, especialmente na resolução de problemas, liderança e trabalho em equipe. Tais conclusões, naturalmente, devem ser avaliadas com cuidado, uma vez que se baseiam em percepções dos próprios titulados.

\section{O discurso crítico de emancipação}

O discurso crítico da emancipação apresenta orientação similar à do discurso da crítica instrumental. Entretanto, adota uma perspectiva ontológica distinta e foca temas próprios. 
De fato, além de caracterizada pela crítica instrumental, a história dos MBAs, no final do século XX, foi também marcada por uma crítica ideológica - manifestada por pesquisadores vinculados à corrente de Critical Management Studies - CMS - (ALVESSON e WILLMOTT, 1992; 1993) - e por ideais humanistas e de emancipação. Tal corrente teve origem no Reino Unido, em cujas universidades haviam se estabelecido alguns grupos de pesquisadores que partilhavam tais ideais. Os trabalhos desses pesquisadores colocavam-se à parte da corrente positivista-funcionalista dominante na academia anglo-saxônica. Estes grupos adotaram perspectivas ontológicas, epistemológicas e linhas de pesquisa caracterizadas por uma abordagem crítica da organização, da vida corporativa e do papel dos executivos.

Pesquisadores vinculados a tais grupos registraram, durante a década de 1990, sua visão sobre os programas de MBA, centrando o foco em três críticas (veja ANTONACOPOULOU, 1999; BOJE, 1996; CHIA, 1996; DEHLER, WELSH e LEWIS, 1999; GOLD, HOLMAN e THORPE, 1999; GREY e FRENCH, 1996; GREY, KNIGHTS e WILLMOTT, 1996; REYNOLDS, 1997; WILLMOTT, 1994). A primeira crítica é de que os MBAs adotavam uma visão instrumental do conhecimento, fomentando a reprodução de receitas e modelos prontos. Com isso, os programas estavam se tornando incapazes de dar conta da complexidade e da diversidade da realidade organizacional. A segunda crítica é de que os programas estavam tratando os estudantes como simples espectadores do processo de ensino e aprendizado, sem adotar métodos que incentivassem a autonomia na busca pela absorção de novos conhecimentos. A terceira crítica é de que os MBAs vinham sofrendo um processo contínuo de transformação dos próprios programas em mercadorias. Sturdy e Gabriel (2000), por exemplo, denunciaram a transformação do MBA em um produto padronizado, associado a símbolos de prestígio e poder, e transacionado como bem comercial por instituições orientadas por estratégias de expansão global.

A partir da metade da década de 1990, surgiram também trabalhos em torno da corrente denominada Critical Management Education - CME -, a qual aplicava a perspectiva crítica à pedagogia, tratando de questões de conteúdo e de método (PERRITON e REYNOLDS, 2004). A CME teve raízes tanto em trabalhos de CMS quanto em trabalhos da corrente da pedagogia crítica, notadamente livros do educador brasileiro Paulo Freire (1970).

O periódico Management Learning se constituiu em uma revista preferencial para a veiculação de trabalhos dessa corrente, por intermédio das contribuições pioneiras de Willmott (1994), Fox (1994), e Grey e Mitev (1995). Este periódico, as divisões voltadas para questões educacionais na conferência de CMS e a criação de uma série de conferências denominada Connecting Learning and Critique proporcionaram uma base para o desenvolvimento da CME (PERRITON e REYNOLDS, 2004).

O foco da CME é questionar os pressupostos e as práticas que caracterizam a educação tradicional em gestão, fundada no gerencialismo. Para os autores afiliados a esta corrente, a atividade de gestão deve ser percebida em termos de seu significado social, moral e político. A educação deve, portanto, desafiar a prática gerencial e, não, sustentá-la (GREY e MITEV, 1995). Para isso, deve basear-se em quatro pressupostos pedagógicos (GREY, KNIGHTS e WILLMOTT, 1996): primeiro, um compromisso com o questionamento moral sobre os fundamentos da teoria e da prática profissional; segundo, ênfase na análise da ideologia e das estruturas subliminares de poder, as quais interagem com questões de raça, classe, idade e gênero; terceiro, a valorização da perspectiva social e comunitária em lugar da perspectiva individual; e quarto, a valorização da emancipação e a busca de uma sociedade mais justa e mais igualitária.

\section{O discurso da mídia}

Além de pesquisadores, também os jornalistas passaram a desenvolver textos sobre os MBAs, constituindo um discurso próprio. Tal discurso, disseminado pela mídia de negócios, distingue-se pelo que Wood Jr. e Paes de Paula (2004) denominaram de caráter redentor. Desde que tal mídia começou a dar atenção ao tema, os MBAs são retratados como caminho seguro para obter sucesso, avançar na carreira, exercer cargos de 
liderança e até ser mais feliz na vida (ver, por exemplo: JACOMINO, 1999; 2000; 2001; GOMES, 1996; SGANZERLA, 1995).

Na mídia de negócios brasileira, o tema da educação executiva e o tema dos MBAs têm sido tratados especialmente pela revista Você S/A e por cadernos especiais dos jornais Valor Econômico, O Estado de São Paulo e Folha de São Paulo. No exterior, as revistas Business Week e The Economist, assim como os jornais Financial Times e The Wall Street Journal cobrem extensivamente o tema; em alguns casos, mantendo seções permanentes e completas em seus websites.

Uma análise geral do conteúdo destes veículos leva a constatar que o objetivo é auxiliar os leitores interessados em formação executiva a escolherem e serem aprovados em programas de prestígio. Observa-se que os aspectos destacados nos artigos são frequentemente os mesmos utilizados como critério nos rankings de programas de MBA. Com isso, universalizam-se os critérios de sucesso, naturalizando-os como objetivos a serem perseguidos pelos profissionais que buscam um MBA. Ao mesmo tempo, consolida-se a noção segundo a qual o MBA é a solução para o atendimento de tais objetivos.

No Brasil, as matérias publicadas são, com certa frequência, traduções ou adaptações daquelas publicadas nas revistas internacionais. Os títulos são significativos da abordagem adotada e do caráter redentor dos conteúdos:

- 4 requisitos para ser aprovado no MBA de Harvard (EXAME, 2013);

- Como entrar nas principais escolas de negócio do mundo (VOCÊ S/A, 2012);

- Os 10 melhores MBAs do mundo para quem quer ser chefe (EXAME, 2013);

- As escolas que garantiram os melhores salários após o MBA (EXAME, 2013).

A publicidade presente na mídia de negócios segue a mesma linha, promovendo a suposta capacidade dos cursos de gerar impacto positivo sobre a carreira dos alunos, conforme se observa nos trechos de peças publicitárias a seguir:

- Escolha a melhor. Estude na BSP - Business School São Paulo (BSP) (EXAME, 2013);

- Uma pós-graduação melhora a sua carreira. A pós-graduação certa muda a sua vida. Universidade Anhembi Morumbi (VOCÊ S/A, 2013);

- Avance sua Carreira com um MBA da Leeds School of Business - Leeds School of Business (BUSINESS WEEK, 2013);

- Quão longe os seus planos de carreira vão? Faça planos maiores com o MBA Executivo da London Business School. - London Business School (THE ECONOMIST, 2013).

Em contraposição a esse discurso, timidamente surgiram também textos críticos aos MBAs e às escolas de negócios. Em geral, tais textos não são "assinados" pelo veículo, porém baseados na opinião ou em pesquisas de acadêmicos e executivos. Por exemplo, John Colley (THE ECONOMIST, 2013), diretor de programas da Nottingham University Business School, criticou a distância entre a academia e a prática de negócios, atribuindo a esta característica a queda de $20 \%$ nas matrículas em MBAs britânicos entre 2008 e 2011 . John C. Beck (FINANCIAL TIMES, 2013), ex-diretor de uma escola de negócios, advoga que não há boas escolas de negócios no mundo, argumentando que as escolas perderam a capacidade de transformar estudantes em profissionais genuínos, dotados de conhecimentos e habilidades que lhes permitam contribuir direta e rapidamente no ambiente de negócios. 
No Brasil, o jornal Valor Econômico (2013) publicou texto sugerindo que a experiência prática vale mais do que um MBA no currículo. Segundo o autor, exceto quando o título vem assinado pelas melhores escolas do mundo, o mercado corporativo já valoriza mais o perfil comportamental e as realizações profissionais. Cita depoimentos de executivos e recrutadores que criticam o processo de "comoditização" dos MBAs, a perda de diferencial competitivo do curso e a falsa crença de que um MBA representa um investimento de retorno garantido.

Dessa forma, o discurso redentor revela fissuras não observadas algumas décadas atrás, que parecem reproduzir, em pequena escala, o discurso da crítica instrumental, apresentado anteriormente. Por outro lado, tais fissuras não "comprometem" o discurso geral, que se mantém fortemente laudatório, conservando seu caráter redentor. Pode-se supor que as fissuras identificadas não comprometem também o papel da mídia na difusão dos MBAs como solução preferencial para profissionais em busca da aceleração da carreira profissional com ambições relacionadas a cargos executivos.

\section{O Discurso dos Alunos}

\section{Métodos}

Para captar o discurso dos participantes de programas profissionais de formação gerencial, realizamos uma pesquisa com alunos de três programas de MBA oferecidos por duas unidades de uma mesma instituição de ensino: Curso 1, um programa de pós-graduação lato sensu credenciado pela AMBA, criado há mais de 40 anos; Curso 2, um programa de pós-graduação stricto sensu (MPA) destinado a alunos com experiência profissional, lançado há 20 anos, inspirado pela estrutura de MBAs internacionais, credenciado pela AMBA, e submetido à avaliação da Coordenação de Aperfeiçoamento de Pessoal de Nível Superior (CAPES); e Curso 3, um programa de pós-graduação lato sensu, destinado a profissionais com, no mínimo, quatro anos de experiência, com abrangência nacional e expressivo número de participantes.

Para cada programa, pesquisamos dois grupos: alunos do último semestre e ex-alunos, formados em 2009, 2010, 2011 e 2012. Optamos pela realização de entrevistas em grupos focais porque esse método possibilita que haja interação entre os participantes, estimulando o fluxo de informações (VERGARA, 2009). As entrevistas foram gravadas por meio de recurso audiovisual. O roteiro de entrevista compreendia os seguintes temas: percepção geral sobre o curso realizado, impacto profissional do curso e desenvolvimento de competências e capacidades. As entrevistas em grupos focais foram realizadas entre 14 de maio e 18 de junho de 2012, e contaram com a participação de 21 alunos e ex-alunos.

Todas as entrevistas foram posteriormente transcritas. A sistematização foi realizada por meio do método de análise de conteúdo, conforme sugerido por Creswell (2010): inicialmente, para uma percepção geral, foi realizada uma leitura completa; em seguida, uma releitura para codificação e organização do material em segmentos de texto; o passo seguinte foi a geração de pequeno número de categorias; e, finalmente, foram interpretados os significados das informações agrupadas.

A análise levou-nos a agrupar a percepção dos participantes dos grupos focais em relação a cinco aspectos dos cursos: interação e troca de experiências, aplicação prática do conhecimento, desenvolvimento da capacidade crítica e analítica, obtenção de credencial e marca no currículo, e impactos na carreira profissional. Nesta seção, a seguir, detalhamos cada um destes aspectos.

\section{Interação e troca de experiências}

Em todos os grupos focais, a troca de experiências foi apontada como principal benefício decorrente da interação com colegas. Ela deriva de duas características dos cursos tidas como essenciais: a experiência 
profissional prévia dos alunos e a diversidade de perfis. Entretanto, pudemos captar nuanças sobre esta característica, frequentemente associada à formação de redes e seu impacto positivo sobre eventuais trocas de emprego e avanço nas carreiras.

De fato, o networking como alavanca para mudança de emprego surgiu apenas entre os participantes do Curso 2. Nos demais, ele aparece como uma troca de cartões superficial e sem consequências relevantes para a carreira. Segundo declarou um dos entrevistados: "[...] lógico que você vai ter troca de cartões. [...] mas na minha turma mesmo eu não vi nada muito além disso [...]” (Aluno do Curso 3).

\section{Aplicação prática do conhecimento}

A utilização de casos é vista como a principal ferramenta dos cursos para aproximar a teoria da prática. Alguns participantes sugeriram a realização de mais trabalhos aplicados a empresas, porém a ideia mais consensual parece ser a de que a aplicação prática dos conhecimentos deve ser de responsabilidade e iniciativa dos alunos.

Com relação aos conhecimentos acumulados, os respondentes citaram como relevantes tanto disciplinas relacionadas a hard skills (finanças e marketing, por exemplo) como disciplinas relacionadas a soft skills (gestão de pessoas e equipes de alto desempenho, por exemplo). Os entrevistados também indicaram que os programas oferecem maior ênfase em disciplinas relacionadas a hardskills. Conforme declarou um deles: "Para algumas coisas não me parece que o [Curso 3] seja o espaço mesmo, mas talvez pudesse ter mais peso em disciplinas que desenvolvem liderança, gestão de pessoas." (Ex-aluno do Curso 3).

Entretanto, isso não é visto como um problema. Conforme indicou uma entrevistada: "[O curso] te obriga na técnica e te deixa a competência [de aplicação] como optativa.” (Ex-aluna do Curso 1).

Especificamente nos grupos do Curso 2 (MPA), os participantes atribuíram parte importante do seu desenvolvimento à dinâmica do curso, ou seja, o alto nível de esforço exigido, o elevado grau de interação entre alunos, a competitividade imposta pela avaliação comparativa (curva forçada) e o rigor acadêmico no processo de elaboração da dissertação. O desenvolvimento pessoal, para os entrevistados, emerge do processo como um todo. Conforme dois deles declararam:

Quanto mais você suar aqui [na escola], menos você vai sangrar lá [empresa]. (Aluno do Curso 2).

[...] eu acho que a própria dinâmica do curso te obriga a, uma hora, ser ouvinte, uma hora ser líder. Te joga na fogueira para isso. Indiretamente, a dinâmica do curso também te leva a exercer alguns papéis [...]. (Aluna do Curso 2).

\section{Desenvolvimento da capacidade crítica e analítica}

O desenvolvimento da capacidade crítica e analítica foi muito associado pelos entrevistados ao que denominaram ampliação da visão. No Curso 1 e no Curso 3, tais capacidades foram associadas ao embasamento teórico e aos conhecimentos adquiridos. No Curso 2, foram associadas à prática de análise de casos, ao processo de desenvolvimento da dissertação e, especificamente, à aprendizagem de métodos científicos. Segundo dois entrevistados:

[...] foi legal a mecânica dos cases, [...] acabou agregando do ponto de vista de fazer análise, propor, ver onde que estão as respostas, que nem sempre tem uma resposta certa. (Aluno do Curso 2). 
Esse processo de fazer uma dissertação, defender para uma banca, [colabora] para a qualidade do trabalho que você apresenta no dia a dia. (Ex-aluno do Curso 2).

\section{Obtenção de credencial e marca no currículo}

O fato de o curso gerar uma nova credencial para o currículo, associada a uma marca específica, é percebido pelos participantes como importante para suas carreiras. Entretanto, diferentes grupos observaram diferentes credenciais ou marcas como relevantes. Alguns entrevistados percebem a marca MBA como mais relevante, enquanto para outros a marca da instituição é mais relevante. Naturalmente, quando os dois fatores estão alinhados, nota-se ainda maior impacto. Segundo declarou um entrevistado: "E uma das coisas que eu tenho falado para quem quer fazer MBA [...] é que a faculdade você pode até fazer uma que não tenha tanto nome, mas o MBA, não." (Aluno do Curso 3).

Especificamente para os entrevistados do Curso 2, a marca MPA parece não ter valor no mercado, uma vez que o curso não é conhecido nas empresas. O que, para eles, faz a diferença no currículo é o título de mestre. De acordo com dois entrevistados: "[...] o título de mestre é que vale na hora que a gente vai para o mercado. [...] é um selo que te qualifica acima de uma grande maioria." (Aluna do Curso 2). "[...] ser stricto sensu é um diferencial, principalmente no Brasil, onde a gente tem a banalização total da sigla MBA [...]." (Ex-aluno do Curso 2).

\section{Impactos na carreira profissional}

Os impactos dos cursos na carreira puderam ser divididos, com base na sistematização dos conteúdos das entrevistas, em três categorias, para as quais foi constatado alto grau de concordância entre os participantes. A primeira categoria refere-se à conquista de repertório e reforço da imagem pessoal, e está relacionada a como o conhecimento adquirido se revela no discurso do profissional e influencia a percepção de pares sobre ele. Nesse sentido, os cursos melhoram a capacidade de o profissional se expressar e dialogar com os outros, além de conferir mais crédito ao seu discurso, impactar na forma como os outros o veem, diferenciando-o, assim, dos demais. A segunda categoria é o aumento da autoconfiança e segurança para se expor e para tomar decisões e mudar de carreira ou de emprego. A terceira categoria é a empregabilidade, que, para os participantes do Curso 1 está associada à ampliação da área de atuação, decorrente de se agregar a formação em Administração à formação mais específica obtida na graduação, geralmente realizada em outra área. No Curso 3, ela decorre do aumento da autoconfiança e da troca de experiências com colegas com trajetórias profissionais diferentes. Já no Curso 2, ela decorre da possibilidade de ingressar na carreira acadêmica e da obtenção do título de mestre, como "diferencial" frente a outros candidatos a determinado emprego ou como "selo de qualidade" para a prestação de serviços de consultoria.

Além desses impactos, os entrevistados percebem mudanças na forma como veem o mundo e o trabalho e na forma como lidam com o que veem. Eles afirmam que o curso "amplia a visão", "abre a mente" e permite "ver o todo". Conforme dois entrevistados declararam: "[...] foi uma exposição bastante interessante a jeitos de pensar e de encarar os problemas totalmente diferentes." (Ex-aluno do Curso 2). "O mundo não é mais o mesmo." (Ex-aluno do Curso 1).

Ao perceber o seu ambiente de uma forma diferente, o participante passa a lidar com ele de modo distinto, a "jogar melhor o jogo". Adquire uma nova postura, que permite que se sinta mais seguro e mais confiante em sua capacidade de realização. 


\section{Discussão}

\section{Discurso e instituições}

Nas seções anteriores, apresentamos e comentamos os cinco discursos sobre os MBAs. Nesta seção, adotamos a perspectiva da análise do discurso para avaliar os cinco discursos apresentados. Pesquisadores que adotam tal perspectiva (PHILLIPS e HARDY, 2002; GRANT, KEENOY e OSWICK, 2001) a definem como a pesquisa sistemática de todas as práticas discursivas, com o objetivo de explicar como tais práticas são produzidas, distribuídas e consumidas. De tal perspectiva, a linguagem é mais do que o espelho da realidade; a linguagem é um meio de construção da própria realidade.

Phillips, Lawrence e Hardy (2004) argumentam que a análise do discurso oferece uma perspectiva conceitual coerente, capaz de explicar os processos que permeiam o fenômeno de institucionalização. Segundo eles, as instituições (MEYER e ROWAN, 1977) são constituídas por meio de discursos. Philips, Lawrence e Hardy (2004) propõem um modelo que ressalta as relações entre textos, discursos, instituições e ação. Segundo tal modelo, ações (condicionadas pelas instituições) geram textos que permeiam o discurso, o qual por sua vez produz instituições. Os autoresadvogam que dois tipos de ação produzem textos de maior impacto: ações caracterizadas pela novidade e grau de surpresa que geram, e ações que colocam em cheque ou afetam a legitimidade de uma organização (ou instituição).

Consideramos nosso foco de análise, o pilar dos MBAs, como um campo institucional constituído por diversos atores, tais como as instituições de ensino, as organizações certificadoras, os órgãos reguladores, o corpo docente, a mídia de negócios, o corpo discente e grupos de pesquisadores. Tais atores interagem, influenciam-se mutuamente e buscam satisfazer seus interesses. Dessa forma, o campo configura-se em uma arena de poder, na qual os atores competem pela definição de temas e da narrativa dominante. Tal narrativa, por sua vez, interfere e ajuda a conformar a realidade do campo institucional (veja MAGUIRE e HARDY, 2006).

\section{Os cinco discursos do MBA}

Nesta pesquisa, identificamos cinco discursos sobre os MBAs. O Quadro 1 sumariza os temas preferenciais de cada discurso. Em seguida, comentamos cada um deles. 
Quadro 1

\section{Discursos e seus temas preferenciais}

\begin{tabular}{|c|c|}
\hline Discursos & Temas preferenciais \\
\hline $\begin{array}{l}\text { Discurso da crítica } \\
\text { instrumental }\end{array}$ & $\begin{array}{l}\text { Foco excessivo no desenvolvimento da capacidade analítica e pouca ênfase na solução de } \\
\text { problemas } \\
\text { Foco excessivo no desenvolvimento de hard skills e incapacidade para desenvolver soft } \\
\text { skills } \\
\text { Distância entre conteúdos ensinados e necessidades das empresas } \\
\text { Impacto duvidoso sobre o desempenho profissional dos alunos } \\
\text { Impacto duvidoso sobre a carreira dos alunos } \\
\text { Corpo discente jovem, sem experiência suficiente para refletir sobre questões de } \\
\text { liderança }\end{array}$ \\
\hline $\begin{array}{l}\text { Discurso da } \\
\text { defesa } \\
\text { instrumental }\end{array}$ & $\begin{array}{l}\text { Percepção de desempenho superior ao de pares que não cursaram MBAs } \\
\text { Impacto significativo nos salários dos alunos após a realização do curso } \\
\text { Aumento da empregabilidade } \\
\text { Ascensão a posições seniores, após a realização do curso } \\
\text { Mudanças de emprego } \\
\text { Abertura de negócios próprios } \\
\text { Aumento do percentual de empresas que buscam profissionais com MBA }\end{array}$ \\
\hline $\begin{array}{l}\text { Discurso crítico de } \\
\text { emancipação }\end{array}$ & $\begin{array}{l}\text { Fomento de uma visão instrumental e simplista do conhecimento, focando a reprodução } \\
\text { de receitas e modelos prontos } \\
\text { Fomento de uma visão conformista e não crítica a respeito das empresas, das estruturas } \\
\text { de poder e do papel dos gestores } \\
\text { Ênfase insuficiente na perspectiva social e comunitária, em detrimento de uma } \\
\text { perspectiva individual } \\
\text { Tratamento dos estudantes como espectadores, sem incentivo à autonomia e ao } \\
\text { protagonismo na busca de novos conhecimentos } \\
\text { Transformação dos programas em mercadorias, com padronização do "produto" }\end{array}$ \\
\hline $\begin{array}{l}\text { Discurso redentor } \\
\text { da mídia de } \\
\text { negócios }\end{array}$ & $\begin{array}{l}\text { Redenção: capacidade de redimir de uma situação difícil ou indesejável, incompatível com } \\
\text { o potencial latente do profissional } \\
\text { Aumento da empregabilidade e da versatilidade } \\
\text { Crescimento pessoal e profissional } \\
\text { Utilitarismo: quais são as melhores escolas e como conseguir ser admitido nelas }\end{array}$ \\
\hline $\begin{array}{l}\text { Discurso } \\
\text { instrumental dos } \\
\text { alunos }\end{array}$ & $\begin{array}{l}\text { Interação e troca de experiências } \\
\text { Aplicação prática do conhecimento: hard skills e soft skills } \\
\text { Desenvolvimento da capacidade crítica e analítica } \\
\text { Obtenção de credencial e marca no currículo: o curso e a instituição } \\
\text { Impactos na carreira profissional: ampliação da visão profissional e habilidades para "jogar } \\
\text { o jogo" }\end{array}$ \\
\hline
\end{tabular}

Fonte: Elaborado pelos autores. 
O discurso da crítica instrumental é produzido por pesquisadores renomados - tais como Michael Porter, Jeffrey Pfeffer, Warren Bennis, Henry Mintzberg e RakeshKhurana -, e frequentemente disseminado em revistas científicas de alto fator de impacto (PORTER e MCKIBBIN, 1988; PFEFFER e FONG, 2002). Tal discurso apresenta-se como "voz de autoridade" e "consciência crítica". Centra-se na percepção dos autores, segundo a qual deveria existir um modelo ideal de MBA, capaz de identificar corretamente as demandas das empresas, articular coerentemente conteúdos e métodos, e capacitar os estudantes a líderes aptos a contribuir de forma substantiva para a melhoria da gestão. De forma implícita, sugere que, se tais condições fossem atendidas, os programas de MBA gerariam impactos positivos sobre as carreiras dos participantes.

O discurso da defesa instrumental é produzido principalmente por associações (ASSOCIATION OF MBAs, 2010), com amparo dos rankings preparados por jornais e revistas da mídia de negócios. Tal discurso apresenta-se como "científico", e seus resultados são sustentados pelo uso de amplas bases de dados. Seu argumento principal é de que os MBAs causam, comprovadamente, efeito positivo na carreira dos estudantes: aumentam sua empregabilidade, geram aumento no salário e permitem maior mobilidade. De forma complementar, indica que as empresas continuam buscando profissionais com MBA, reconhecendo assim que seu desempenho é superior ao de profissionais que não o fizeram. Tal discurso contrapõe-se parcialmente ao discurso da crítica instrumental, por focar apenas temas relacionados ao impacto dos MBAs sobre as carreiras dos participantes.

O discurso crítico de emancipação tem sua produção em textos gerados por uma corrente periférica de pesquisadores - tais como Christopher Grey, Robert French e Hugh Wilmott -, que partilham perspectivas ontológicas e epistemológicas críticas (WILLMOTT, 1994). Em tal discurso, procura-se equilibrar a ideia de emancipação - o estudante como protagonista do processo de aprendizado e consciente do impacto social de seu futuro papel de gestor - com uma visão pragmática - um processo de ensino e aprendizado que atenda às necessidades das empresas. De forma complementar, os pesquisadores vinculados a tal discurso criticam o processo de transformação dos MBAs em mercadorias (STURDY e GABRIEL, 2000). Tal discurso complementa o discurso da crítica instrumental, tendo um alcance mais restrito do que este último. O discurso crítico da emancipação não parece ter chegado até a mídia de negócios, como o discurso da crítica instrumental (THE ECONOMIST, 2013), ou provocado discursos de defesa. No entanto, pode-se supor que tenha gerado impactos pela própria ação dos professores associados às correntes críticas citadas anteriormente (CMS e CME) de forma direta nos programas nos quais atuam como docentes.

O discurso redentor da mídia de negócios é produzido por revistas e jornais especializados, com ampla disseminação entre empresas e profissionais interessados em realizar programas de MBA. Seu caráter de superfície é eminentemente utilitário: fornecer aos interessados informações úteis e atualizadas sobre as instituições de ensino e sobre seus programas. No entanto, por detrás desse serviço, deve-se considerar que tal cobertura, com destaque para os rankings, tornou-se uma atividade comercial importante para as publicações, capaz de atrair leitores e anunciantes. Coerentemente com tal modelo, os textos parecem ter mantido, ao longo das últimas décadas, seu caráter redentor (WOOD JR. e PAES DE PAULA, 2004). No entanto, a mídia de negócios começa a abrir espaço para textos de crítica instrumental. Tal fato reflete a proeminência do discurso da crítica instrumental e, provavelmente, uma estratégia de busca de legitimidade do discurso da mídia, temperando sua visão mais laudatória com perspectivas mais críticas.

O discurso instrumental dos alunos foi gerado por entrevistas em grupos focais. Os registros obtidos e analisados permitem concluir que os textos (entrevistas) dos estudantes se alinham, em termos de temas, com aqueles presentes nos discursos da crítica instrumental, da defesa instrumental e da mídia de negócios. Os entrevistados se preocupam com o impacto do programa em suas carreiras, com a obtenção de uma credencial para o currículo e com a aquisição de novos conhecimentos e de novas habilidades. Eles têm, em geral, uma visão positiva dos programas que cursam e reconhecem a contribuição destes para o desenvolvimento de sua capacidade crítica e analítica. Tais resultados corroboram aqueles encontrados por Ruas e Comini (2007) em pesquisa realizada entre 2003 e 2006 com cerca de 300 alunos de MPAs, MBAs e cursos de especialização em nível de pós-graduação de diferentes instituições brasileiras. 


\section{Em busca de uma nova narrativa: interações e disputas discursivas}

O pilar do MBA pode ser visto como um campo institucional (ou subcampo institucional, se tomarmos a indústria do management como campo institucional), no qual diferentes agentes empregam distintas estratégias discursivas, de acordo com suas perspectivas ontológicas e seus interesses individuais. Dessa forma, tal campo institucional se configura como uma arena política aberta, sem uma agenda específica ou prazos para decisões. Nesta condição, diferentes agentes avaliam o campo, identificam temas e produzem textos, procurando realizar ações de influência. Alguns destes textos, seja pela originalidade ou pela contundência, ganham maior impacto, contribuindo assim para a construção ou alteração de um determinado discurso (PHILLIPS, LAWRENCE e HARDY, 2004).

Como não há um locus preciso para as disputas discursivas, os agentes disseminam seus textos em múltiplas frentes. Por exemplo, a revista Academy of Management Learning \& Education se tornou um veículo usual para veiculação de textos relacionados ao discurso da crítica instrumental, enquanto a revista Management Learning atraiu textos relacionados ao discurso da crítica de emancipação.

Observando-se o campo, pode-se especular que não há, em geral, embates frontais. A disputa discursiva parece caracterizar-se pela existência de múltiplos textos, disseminados em revistas, congressos e reuniões, os quais são absorvidos de forma heterogênea e, eventualmente, incorporados, gerando microações de mudança.

Nessa arena, há vários centros de decisão: primeiro, as organizações certificadoras (como a AMBA), capazes de assimilar ideias, gerar textos e incorporar critérios que influenciariam o comportamento das instituições de ensino afiliadas; segundo, os órgãos reguladores (como a CAPES), aptos a realizar processos similares aos das certificadoras, porém com um poder ainda maior de determinar mudanças; terceiro, as instituições de ensino, que podem também absorver ideias e realizar processos de mudanças em seus programas; e, quarto, os professores, que, individualmente, com algumas restrições, alterariam conteúdos e métodos em seus cursos. Dessa forma, os embates discursivos podem ocorrer em diferentes níveis, de forma simultânea ou não, e de forma convergente ou divergente entre os níveis. Cabe, então, perguntar: será possível, mediante diferentes discursos, construir ou reconstruir a narrativa do MBA?

Narrativas são textos captados por meio dos discursos disponíveis, com um início, um fim e uma sequência cronológica clara (veja CZARNIAWSKA, 1998). A narrativa histórica do MBA, construída pelas escolas de negócios, e disseminada com vigor pela mídia de negócios, tinha como personagem o indivíduo, como início uma ambição de carreira, como fim uma posição sênior de liderança, e como sequência cronológica a admissão em uma escola de renome, o desenvolvimento de hard skills e de soft skills, o estabelecimento de uma boa rede de relacionamentos, o estudo de caso e a formação generalista.

Embora tenha sido desafiada, essa narrativa ainda não foi substituída. Proponentes indicam que o novo personagem é um indivíduo socialmente consciente e responsável; o início continua sendo uma ambição, porém uma ambição de mudança qualitativa, mais do que uma simples ambição de carreira; o fim pode ser uma posição sênior de liderança, mas pode também ser um empreendimento próprio, com fins lucrativos ou sociais; e a sequência cronológica passa a incluir atividades de aplicação prática do conhecimento, experiências em contextos culturais diversos e o desenvolvimento de uma visão crítica das organizações e da atividade gerencial.

Como tal narrativa irá se estabelecer em cada país, região, instituição de ensino ou programa é difícil prever. Pode-se, entretanto, tomar como hipótese que a diversidade de contextos irá gerar grande diversidade de modelos, com proliferação de tipos híbridos, que mesclem de forma variada características de diferentes discursos. 


\section{Conclusão}

\section{Síntese}

Observou-se, nos últimos anos, um grande crescimento na oferta e popularidade dos MBAs no Brasil e no mundo. Segundo Khurana (2007), o MBA tornou-se um pré-requisito para a conquista de cargos no alto escalão de grandes empresas. Apesar dessa popularidade e de o primeiro MBA ter surgido há mais de um século, as críticas sobre a sua capacidade de desenvolver as competências necessárias ao trabalho gerencial, de lidar com as questões práticas do mundo dos negócios e de formar gestores éticos colocam seu modelo em xeque.

Tais críticas baseiam-se principalmente nos programas de MBA norte-americanos, que, embora tenham servido de modelo para a criação dos cursos brasileiros, apresentam diferenças substantivas em relação a estes. Além disso, os programas brasileiros também apresentam marcantes diferenças entre si. Temos, no país, MPAs, MBAs generalistas e MBAs especializados, e ainda diversos tipos de cursos de pós-graduação em formação gerencial que não adotam a sigla MBA, mas possuem muitas características comuns com estes programas.

Este trabalho situou o fenômeno dos MBAs dentro do fenômeno maior da indústria do management, que vem, desde a década de 1990, desenvolvendo-se e reforçando seu papel na disseminação de ideias e modelos de gestão. Identificamos e estudamos, da perspectiva da análise do discurso, cinco discursos: o discurso da crítica instrumental, o discurso da defesa instrumental, o discurso crítico de emancipação, o discurso redentor da mídia de negócios e o discurso instrumental dos alunos. Concluímos que MBA pode ser visto como um campo institucional aberto, no qual diferentes agentes empregam distintas estratégias discursivas, de acordo com suas perspectivas ontológicas e seus interesses.

\section{Contribuições do estudo}

Este estudo apresenta as seguintes contribuições. Primeiro, a revisão de literatura e textos sobre MBAs na forma de quatro discursos estabelecidos, e a identificação de seus temas preferenciais. Segundo, a perspectiva da análise do discurso, adotada no estudo, chama a atenção para o papel que as estratégias discursivas têm nas dinâmicas que podem gerar mudanças em um campo institucional, especificamente no campo institucional dos MBAs. Terceiro, são identificados os agentes envolvidos diretamente nas estratégias discursivas, e apontados suas motivações e limitações. Quarto, a incorporação do discurso dos alunos, com identificação de seus principais temas e respectivos textos.

\section{Limitações e futuros estudos}

Este estudo apresenta algumas limitações. A primeira origina-se do próprio escopo do estudo, que compreendeu vários discursos, obrigando a um tratamento pouco profundo de cada um deles. Futuros estudos poderão ampliar e aprofundar o entendimento do discurso da mídia, realizando uma análise mais ampla dos conteúdos por ela vinculados. Poderão também ampliar e aprofundar o entendimento do discurso dos alunos por meio de uma amostra mais ampla de programas.

A segunda limitação refere-se à caracterização de cada discurso. Procuramos, com base em trabalhos científicos existentes e do material coletado, definir as características básicas de cada discurso estudado, provendo-lhe certa identidade. Entretanto, devemos aceitar que tais discursos não são monolíticos e alguns deles apresentam considerável diversidade interna. Futuros estudos poderão tentar capturar tal condição, de forma a revelar os diversos textos que compõem os diferentes discursos. 
A terceira limitação refere-se à adoção da perspectiva da análise do discurso. Naturalmente, acreditamos que tal perspectiva constitui uma lente poderosa, capaz de revelar as dinâmicas por detrás do fenômeno dos MBAs. No entanto, devemos aceitar que certas iniciativas e estratégias de mudança, embora relevantes, podem não ter sido evidenciadas por textos e discursos. Futuros estudos poderão identificar o papel dessas estratégias e avaliar seu impacto na evolução do campo institucional do MBA.

\section{Referências}

ALVESSON, M.; KÄRREMAN, D. Varieties of discourse: on the study of organizations through discourse analysis. Human Relations, v. 53, n. 9, p. 1125-1149, 2000.

; WILLMOTT, H. Critical Management Studies. London: Sage, 1992.

(Eds.). Making sense of management: a critical analysis.London: Sage, 1993.

ANTONACOPOULOU, E. P. Teaching 'critical thinking' to MBAs. In: INTERNATIONAL CRITICAL MANAGEMENT STUDIES CONFERENCE, 1., July 1999, Manchester. Proceedings... Manchester: UMIST, 1999.

ASSOCIATION OF MASTERS IN BUSINESS ADMINISTRATION. Criteria for the acreditation of MBA programmes. Disponível em: <http://www.mbaworld.com>. Acesso em: 26 fev. 2012.

Research \& Consultancy Centre. 2010 Career Survey. Londres, 2010. Disponível em: <http://www.mbaworld.com/publications〉. Acesso em: 17 mar. 2012.

BALDWIN, T. T. et al. The elusiveness of applied management knowledge: a critical challenge for management educators. Management Learning, v. 10, n. 4, p. 583-605, 2011.

BENNIS, W. G.; O’TOOLE, J. How business schools lost their way. Harvard Business Review, v. 83, n. 5, p. 96-104, 2005.

BOJE, D. M. Management education as a panoptic cage. In: FRENCH, R.; GREY, C. (Eds.) Rethinking management education. Sage: London, 1996. p. 172-195.

BUSINESSWEEK. Business school rankings $\boldsymbol{\&}$ profile. Disponível em: <http://www.businessweek.com/bschools/rankings/>. Acesso em: 06 nov. 2011.

. Nova York: Ed. Bloomberg LP. 22-28 abr. 2013.

CHIA, R. Teaching paradigm shifting in management education: University Business Schools and the entrepreneurial imagination. Journal of Management Studies, v. 33, n. 4, p. 409-428, 1996.

COOKE, B.; WOOD JR., T.; MACAU, F. Brazilian management gurus as reflexive soft HRM practitioners: an empirical study. International Journal of Human Resource Management, v. 24, n. 1, p. 110-129, 2013.

COSTA, A. S. M.; BARROS, D. F.; MARTINS, P. E. M. A alavanca que move o mundo: o discurso da mídia de negócios sobre o capitalismo empreendedor. Cad. EBAPE.BR, v. 10, n. 2, p. 100-120, 2012.

CRESWELL, J. W. Projeto de pesquisa: métodos qualitativo, quantitativo e misto. 3. ed. Porto Alegre: Artmed, 2010.

CZARNIAWSKA, B. A narrative approach to organization studies. Thousand Oaks, CA: Sage, 1998.

DEHLER, G.; WELSH, M. A.; LEWIS, M. W. Critical pedagogy in the "new paradigm": raising complicated understanding in management learning. In: INTERNATIONAL CRITICAL MANAGEMENT STUDIES CONFERENCE, 1., July 1999, Manchester. Proceedings... Manchester: UMIST, 1999. 
DONADONE, J. C. Imprensa de negócios, dinâmica social e os gurus gerenciais. In: ENCONTRO NACIONAL DE ESTUDOS ORGANIZACIONAIS, 1., 2000, Curitiba. Anais... Curitiba: ENEO, 2000. 1 CD-ROM.

In the word of intermediaries: consulting firms, business press and the reorganization of the management activities. Saarsbrücken: VDM Verlag, 2010.

EXAME. O MBA de Harvard, segundo duas brasileiras. Disponível em: <http://exame.abril.com.br/carreira/noticias/o-mba-de-harvard-segundo-duas-brasileiras?>. Acesso em: 01 fev. 2013.

As 20 melhores escolas para fazer um MBA nos EUA. Disponível em: <http://exame.abril.com.br/carreira/mba/noticias/as-20-melhores-escolas-para-fazer-um-mba-nos-eua>. Acesso em: 04 jun. 2013 .

As melhores escolas de negócios para ter "vida social". Disponível em: <http://exame.abril.com.br/carreira/mba/noticias/as-melhores-escolas-de-negocios-para-ter-vida-social>. Acesso em: 04 jun. 2013.

Os 10 melhores MBAs do mundo para quem quer ser chefe. Disponível em: <http://exame.abril.com.br/carreira/mba/noticias/os-10-melhores-mbas-do-mundo-para-quem-quer-ser-chefe> . Acesso em: 04 jun. 2013.

______. Os 10 melhores MBAs para empreendedores. Disponível em: <http://exame.abril.com.br/pme/noticias/os-10-melhores-mbas-para-empreendedores>. Acesso em: 04 jun. 2013.

As escolas que garantiram os melhores salários após o MBA. Disponível em: <http://exame.abril.com.br/carreira/mba/noticias/as-30-escolas-com-formandos-de-mba-mais-bem-pagos>. Acesso em: 06 jun. 2013.

Os melhores MBAs para quem trabalha com TI. Disponível em: <http://exame.abril.com.br/carreira/mba/noticias/os-melhores-mbas-para-quem-trabalha-com-ti>. Acesso em: 06 jun. 2013.

FINANCIAL TIMES. Business school rankings. Disponível em: <http://www.ft.com/intl/businesseducation/mba>. Acesso em: 6 nov. 2011.

Management education needs a real world mindset. Disponível em: <http://www.ft.com/intl/cms/s/2/3e59496c-b40b-11e2-ace9-00144feabdc0.html\#axzz2Vr92ZuRb>. Acesso em: 10 jun. 2013.

FONTENELLE, I. A. Consumo como investimento: a produção do consumidor saudável pela mídia de negócios. Comunicação, Mídia e Consumo, v. 9, n. 24, p. 133-152, 2012.

FOX, S. Debating management learning: II. Management Learning, v. 25, n. 4, p. 579-597, 1994.

FREIRE, P. Pedagogy of the oppressed. New York: Continuum, 1970.

GOLD, J.; HOLMAN, D.; THORPE, R. The manager as a critical reflective practitioner: uncovering arguments at work. In: INTERNATIONAL CRITICAL MANAGEMENT STUDIES CONFERENCE, 1., July 1999, Manchester. Proceedings... Manchester: UMIST, 1999.

GOMES, M. T. MBA ajuda? Exame, 23 out. 1996.p. 47-54.

GOSLING, J.; MINTZBERG, H. Management education as if both matter. Management Learning, v. 37, n. 4, p. 419428, 2006.

GRADUATE MANAGEMENT ADMINISSION COUNCIL. Corporate recruiters survey. Reston, Virginia, 2012. Disponível em: <http://www.gmac.com/market-intelligence-and-research/market-research/gmac-surveys/corporaterecruiters-survey.aspx>. Acesso em: 10 fev. 2012. 
GRANT, D.; KEENOY, T.; OSWICK, C. Organizational discourse: key contributions and challenges, International Studies of Management and Organization, v. 31, n. 3, p. 5-24, 2001.

GREENWOOD, R.; SUDDABY, R.; HININGS, C. R. Theorizing change: the role of professional associations in the transformation of institutionalized fields. Academy of Management Journal, v. 45, n. 1, p. 58-80, 2002.

GREY, C.; FRENCH, R. Rethinking management education: an introduction. In: FRENCH, R.; GREY, C. (Eds.). Rethinking management education. Sage: London, 1996. p. 1-17.

; KNIGHTS, D.; WILLMOTT, H. Is a critical pedagogy of management possible? In: FRENCH, R.; GREY, C. (Eds.). Rethinking management education. Sage: London, 1996. p. 94-110.

; MITEV, N. Management education: a polemic. Management Learning, v. 26, n. 1, p. 73-90, 1995.

HARDY, C.; PHILLIPS, N. No joking matter: Discursive struggle in the Canadian refugee system. Organization Studies, v. 20, n. 1, p. 1-24, 1999.

HUNT, S. D.; SPECK, P. S. Specialization and the MBA: is the broad MBA passé? California Management Review, v. 29 , n.3, 159-175, 1986.

JACOMINO, D. A meta é um MBA. Você S. A., n. 12, jun. 1999. p. 100-103.

Quem são os brasileiros que fazem MBA lá fora. Você S. A., n. 21, p. 17, mar. 2000.

. Os melhores MBAs do planeta. Você S. A., n. 32, p. 24, fev. 2001.

KHURANA, R. From higher aims to hired hands: the social transformation of American business schools and unfulfilled promise of management as a profession. Princeton, NJ: Princeton University Press, 2007.

MAGUIRE, S; HARDY, C. The emergence of new global institutions: a discursive perspective. Organization Studies, v. 21, n. 1, p. 7-29, 2006.

MEYER, J. W.; ROWAN, B. Institutionalized organizations: formal structure as myth and ceremony. American Journal of Sociology, v. 83, n. 2, p. 340-363, 1977.

MICKLETHWAIT, J.; WOOLDRIDGE, A. Os bruxos da administração: como entender a babel dos gurus empresariais. Rio de Janeiro: Campus, 1998.

MINTZBERG, H. Managers not MBAs: a hard look at the soft practice of managing and management development. San Francisco: Berret-Koehler, 2004.

OLIVEIRA, N. N. B. de. Caminhos da paragerência: trajetórias, experiências e expectativas entre formandos de administração de empresas de uma universidade privada em São Paulo. São Paulo: USP, 2008

PAES de PAUlA, A. P.; WOOD JR, T. Pop-management. Revista Ciência Empresarial, Curitiba, n. 2, p. 17-34, 2002.

PERRITON, L.; REYNOLDS, M. Critical management education: from pedagogy of possibility to pedagogy of refusal. Management Learning, v. 35, n. 1, p. 61-77, 2004.

PERSONINI CRUZ, J. F. Percepção dos alunos sobre o impacto de curto prazo dos cursos de MBA em suas carreiras. Dissertação (MPA), FGV-EAESP, 2013.

PFEFFER, J.; FONG, C. T.The end of business schools? Less success than meets the eye. Academy of Management Learning \& Education, v. 1, n. 1, p. 78-95, 2002.

PHILLIPS, N.; HARDY, C. Understanding discourse analysis. Thousand Oaks, CA: Sage, 2002. 
; LAWRENCE, T. B.; HARDY, C. Discourse and institutions.Academy of Management Review, v. 29, n. 4, p. 635-652, 2004

PORTER, L.; MCKIBBIN, L. Management education and development: drift or thrust into the 21st century. New York: McGraw-Hill, 1988.

REYNOLDS, M. Towards a critical management pedagogy. In: BURGOYNE, J.; REYNOLDS, M. (Eds.) Management learning: integrating perspectives in theory and practice. London: Sage, 1997. p. 312-338.

RUAS, R.; COMINI, G. M. Aprendizagem e desenvolvimento de competências: articulando teoria e prática em programas de pós-graduação em formação gerencial. Cad. EBAPE, v. 5, n. Edição Especial, p. 1-14, 2007.

RUBIN, R. S.; DIERDORFF, E. C. How relevant is the MBA? Assessing the alignment of required curricula and required managerial competencies. Academy of Management Learning \&Education, v. 8, n. 2, p. 208-224, 2009.

SGANZERLA, V. Vale a pena fazer um MBA lá fora? Exame, 6 de dez. de 1995. p. 108-110.

SLATER, D. J.; DIXON-FOWLER, H. R. The future of the planet in the hands of MBAs: an examination of CEO MBA education and corporate environmental performance. Academy of Management Learning \& Education, v. 9, n. 3, p. 429-441, 2010.

STURDY, A.; GABRIEL, Y. Missionaires, mercenaries or car salesmen?MBA teaching in Malaysia. Journal of Management Studies, v. 37, n. 7, p. 979-1002, 2000.

THE ECONOMIST. Academic view: Death by distance. Disponível em: <http://www.economist.com/whichmba/academic-view-death-distance>. Acesso em: 10 jun. 2013.

VALOR ECONÔMICO. Experiência vale mais que MBA no currículo. Disponível em: < http://www.valor.com.br/carreira/2527422/experiencia-vale-mais-que-mba-no-curriculo >. Acesso em: 11 jun. 2013.

VERGARA, S. C. Métodos de coleta de dados no campo. São Paulo: Atlas, 2009.

WILlMOTT, H. Management Education: provocations to a debate. Management Learning, v. 25, n. 1, p. 105-136, 1994.

WOOD JR, T.; CALDAS, M. P. Rindo do quê? Como consultores reagem ao humor crítico e à ironia sobre sua profissão. Organizações \& Sociedade, v. 12, n. 34, p. 83-112, 2005.

; PAES DE PAULA, A. P. O fenômeno dos MPAs brasileiros: hibridismo, diversidade e tensões. RAE Revista de Administração de Empresas, v. 44, n. 1, p. 116-129, 2004.

; $\quad$. Pop-management literature: popular business press and management culture in Brazil. Canadian Journal of Administrative Sciences, v. 25, n. 3, p. 185-200, 2008.

ZHAO, J. J. et al. Less success than meets the eye? The impact of Master of Business Administration education on graduates careers. Journal of Education for Business, v. 81, n. 5, p. 261-268, 2006. 